\title{
An Empirical Study of Employees' Tacit Knowledge Sharing Behavior
}

\author{
Juanru WANG \\ School of Management, Northwestern Polytechnical University, Xi'an 710072, China \\ E-mail:wjuanru@nwpu.edu.cn \\ Jin YANG \\ School of Humanities, Economics and Law, Northwestern Polytechnical University, Xi'an 710072, \\ China \\ E-mail: jinyang@nwpu.edu.cn
}

\begin{abstract}
This paper is to investigate how employees' tacit knowledge sharing behavior is influenced by various antecedents. We propose that tacit knowledge sharing consists of three specific behaviors (i.e., socialization, externalization, and internalization) and they are influenced by four antecedents (trust, self-efficacy, knowledge tacitness, and IT support). A survey was conducted to collect data from 258 knowledge workers who worked on complex product development projects. Structural equation modeling was used to analyze the data. The results demonstrate that trust, self-efficacy, knowledge tacitness, and IT support significantly affect the externalization and internalization behaviors, and trust and IT support significantly affect the socialization behavior. This study is helpful to organizations where it is critical for employees to share tacit knowledge. It suggests that tacit knowledge is difficult to share and organizations should nurture mutual trust between employees, enhance their self-efficacy, and provide sufficient IT support so that they are more likely to engage in tacit knowledge sharing.
\end{abstract}

Keywords tacit knowledge; knowledge sharing; trust; self-efficacy; IT support

\section{Introduction}

It is recognized that the resources of an organization have been shift from tangible assets such as land and capital to knowledge, and knowledge has become one of the fundamental resources for an organization ${ }^{[1]}$. As intangible, valuable, rare and inimitable asset, knowledge is the most powerful engine of production ${ }^{[2]}$. However, while tangible resources are relatively easy to acquire and transfer, knowledge is intangible and difficult to reproduce.

Knowledge can be classified into explicit knowledge and tacit knowledge. Explicit knowledge is considered to be totally codifiable and transferable in a formal systematic language, while tacit knowledge is more difficult to formalize and communicate even in an informal atmosphere. The characteristics of tacit knowledge are complexity, idiosyncrasy, ambiguity, and partially understood, which make it hard to imitate by others ${ }^{[3]}$. Most researchers think that tacit

Received July 3, 2014, accepted August 13, 2014

Supported by the National Natural Scientific Foundation (71371154, 71001085), Shaanxi Natural Scientific Foundation (2014JM9361), and Shaanxi University Humanities and Social Science Talent Plan (2014-09) 
knowledge is the foundation for building sustainable competitive advantages in an organization, so it must be somehow codified or shared using communication mechanisms, otherwise, the organization's competitiveness based on tacit knowledge will not sustain. Polanyi ${ }^{[4]}$ emphasized that tacit knowledge is based primarily on doing rather than cognition, a person therefore can do more than he or she knows. Moreover, Botkin and Seeley ${ }^{[5]}$ estimated, eighty percent of knowledge is tacit, yet one of the most difficult tasks of knowledge management remains to facilitate the transfer of tacit knowledge into explicit knowledge. Therefore, tacit knowledge sharing has become an important issue for organizations.

Tacit knowledge sharing is the behavior of an employee to distribute acquired tacit knowledge to others within an organization, which is a complex and complicated process ${ }^{[6]}$. Tacit knowledge sharing can improve organization performance and innovativeness, and influence the speed of knowledge deployment inside an organization ${ }^{[7,8]}$. Since tacit knowledge is difficult to imitate, transfer and replicate, it is important to understand how tacit knowledge sharing behavior can take place. Nonaka and Takeuchi ${ }^{[9]}$ suggested four modes of tacit and explicit knowledge sharing: Socialization (from tacit to tacit), externalization (from tacit to explicit), combination (from explicit to explicit), and internalization (from explicit to tacit). As combination is the process by which explicit knowledge is converted into explicit knowledge, the other three activities of socialization, externalization, and internalization are used in this study, and to explore the process of employees' tacit knowledge sharing behaviors. Prior works make investigation about what predicts knowledge sharing behaviors and how to increase knowledge sharing ${ }^{[10]}$. Some researchers recognize that communication and interpersonal relationships are the critical factors influencing knowledge sharing ${ }^{[11]}$, others think that trust and interpersonal familiarity are positively correlated with people's willingness to share knowledge ${ }^{[12,13]}$. Besides personal factors, the past research have shown, organizational components also can significantly influence the transfer of tacit knowledge ${ }^{[14]}$. However, in so far, influencing factors on knowledge sharing behavior, especially on tacit knowledge sharing behavior has not been fully understood.

In light of the above analysis, we think one of the limitations in current research on knowledge sharing is that, it has rarely differentiated in an explicit manner between explicit knowledge and tacit knowledge, and there are also few empirical studies on the tacit knowledge sharing behavior. Tacit knowledge is very personal, deeply rooted in an employee's action, and influenced by employee's ideal, value, or emotion. Although, tacit knowledge is very difficult to sharing, it can be achieved by employee's action and behavior. Therefore, it is necessary to emphasize that tacit knowledge sharing behavior how to occur in organization. Build on the extant research, the purpose of this paper is to explore factors influencing employee's tacit knowledge sharing behavior from the personal (self-efficacy), interpersonal (trust), knowledge based (tacitness) and IT based (IT support) perspectives, thus providing a relatively holistic coverage of antecedents of tacit knowledge sharing behavior.

\section{Theory and Hypothesis}

According to the existing research on tacit knowledge sharing, a research model was created to explain why an employee is willing to share tacit knowledge (see Figure 1). It is proposed that an employee's tacit knowledge sharing can be classified into socialization behavior, ex- 
ternalization behavior, and internalization behavior, and that trust, self-efficacy, knowledge tacitness, and IT support are associated with these three behaviors. We discuss the theory and hypotheses as follows.

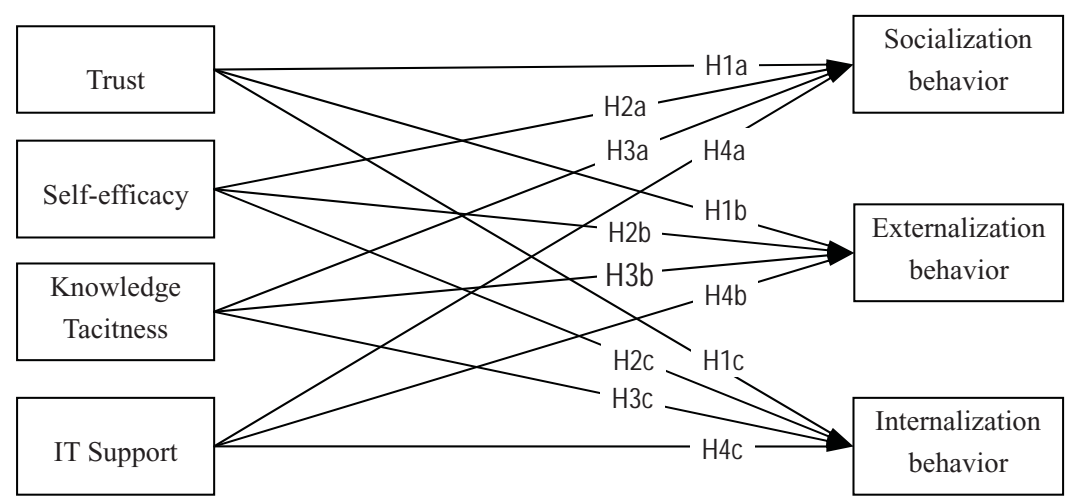

Figure 1 Research model

\section{$2.1 \quad$ Trust}

Trust is a psychological state in which an employee is willing to be vulnerable to another employee based on the belief that the latter will perform a particular action in the absence of the former's monitoring or control ${ }^{[15]}$. Trust plays an important role in facilitate employees' knowledge sharing with others.

Developed in a social and cultural context, trust is prerequisite for tacit knowledge sharing. The existence of a trusting relationship between employees, suggests an environment in which a high degree of sharing is possible. Many studies have indicated that trust is related to knowledge-sharing, in the trust atmosphere, employees are more willing to sharing knowledge ${ }^{[16]}$. This was further demonstrated by Holste and Fields ${ }^{[17]}$, Yang and Farn ${ }^{[18]}$, who found that trust, has a significant effect on tacit knowledge sharing. A similar point was made by Nelson and Cooprider ${ }^{[19]}$, who suggest that trust is the key factor to influencing knowledge sharing behavior, and Renz ${ }^{[20]}$ also provided empirical evidence that trust in management facilitates knowledge sharing by reducing fear of loss of one's unique value. Therefore, a trusting person is more willing to provide useful knowledge to others, and trust among people contributes to improvement in knowledge sharing behavior among employees. In addition, Holste ${ }^{[12]}$ and Choi ${ }^{[21]}$ have carried out empirical studies about the role of trust in the field of knowledge management, and the findings suggest that trust is important for knowledge management, particularly for willingness to share knowledge. Personal relationships had the greatest impact on the sharing of tacit knowledge between employees ${ }^{[22]}$, and trust can increase the quality of knowledge sharing in virtual communities ${ }^{[23]}$. Hence, employee with greater trust will have more opportunities of accessibility and a better chance of knowledge being shared in organization ${ }^{[24]}$.

Based on these evidences, we contend that, in order for tacit knowledge to be successfully shared within organizations, trust between employees is necessary. The stronger the trust is, the greater the intensity of the socialization activities, such as direct interaction, brainstorming, and informal meetings. When people trust each other they do not fear losing knowledge-based power, 
as a result of letting others peek into their brain. Thus, they will be more willing to engage in externalization behaviors, and convert their tacit knowledge into explicit knowledge. Trust also is very important for creating a favorable atmosphere of learning by doing to accumulate internalization behaviors. Based on the above discussion, we predict the followings:

H1a: Trust will have a positive effect on employees' socialization behavior in tacit knowledge sharing.

H1b: Trust will have a positive effect on employees' externalization behavior in tacit knowledge sharing.

H1c: Trust will have a positive effect on employees' internalization behavior in tacit knowledge sharing.

\subsection{Self-efficacy}

Self-efficacy is a form of self-assessment that influences an employee's behavior. It is an expectation whether or not one can reach a certain performance level, undertake a specific behavior, or attain a certain learning goal. Self-efficacy reflects the belief that one possesses the skills and abilities to successfully accomplish a specific task ${ }^{[25]}$. Bandura and Locke ${ }^{[26]}$ suggested that self-efficacy is a proven mediator of the relationship between input variables such as assigned goals or persuasion, and outcome variables such as effort, personal goal setting, and performance. Self-efficacy has been shown to play an important role in influencing employees' motivation and behavior ${ }^{[27]}$. Research in the field of knowledge management has found the importance of self-efficacy on an employee's intention to share knowledge, and the motivations for performing a behavior do not stem from the goals themselves, but from the self-evaluation that is made conditional on their fulfillment ${ }^{[26]}$. It is widely accepted that mastery experience is the most important factor determining self-efficacy, in other words, success raises self-efficacy, while failure lowers it. In this study, self-efficacy is one's confidence in his or her ability to share tacit knowledge with others or articulate tacit knowledge to others. Through sharing useful knowledge, employee feels more confident in what he or she can do. Therefore, self-efficacy in the ability to share tacit knowledge should predict actual tacit knowledge sharing behavior.

The past research supports the thoughts that belief in the ability to share tacit knowledge will positively predict the action of sharing tacit knowledge. As Bandura ${ }^{[28]}$ postulated, selfefficacy determines the willingness of an employee to perform certain activities, Elias et al. ${ }^{[29]}$ concluded that self-efficacy influences employees' adjustment behavior, and a study conducted by Oliver and Shapiro ${ }^{[30]}$ found that the stronger the employee's self-efficacy is, the more effort the employee would put forth to try to obtain the desired results. This means that when an employee has stronger knowledge sharing self-efficacy, he or she will make even greater efforts to successfully complete the knowledge sharing behavior and have positive expectations of behavioral outcomes. It is further demonstrated by Bock and Kim ${ }^{[31]}$, who discovered that selfefficacy could be treated as a major source of motivation for knowledge sharing. In contrast, Endres et al. ${ }^{[32]}$ found self-efficacy facilitates tacit knowledge sharing. Therefore, employee who has high self-efficacy will be more likely to perform related behaviors than those with low self-efficacy, and self-efficacy promotes the sharing of tacit knowledge.

We believe that employees with a higher self-efficacy may share their tacit knowledge more willingly than employees with low self-efficacy, because employees with higher self-efficacy would 
formulate a positive judgment on their capabilities, which would motivate them to share their tacit knowledge. Thus, when an employee has a strong self-efficacy, he or she will have a greater willingness to provide tacit knowledge to others, which intensifies employee's socialization behavior. Self-efficacy could enhance motivations to practice the transfer of tacit knowledge into explicit forms such as written descriptions, narratives, or pictures and diagrams that facilitate externalization behavior. With strong self-efficacy, one will feel more confident in assimilating the experiences and concepts of others into his or her own tacit knowledge, and thus the internalization behaviors will accumulate. Therefore, self-efficacy promotes employee's socialization behavior, externalization behavior, and internalization behavior. Based on the above discussion, we predict the followings:

H2a: Self-efficacy will have a positive effect on employees' socialization behavior in tacit knowledge sharing.

H2b: Self-efficacy will have a positive effect on employees' externalization behavior in tacit knowledge sharing.

H2c: Self-efficacy will have a positive effect on employees' internalization behavior in tacit knowledge sharing.

\subsection{Knowledge Tacitness}

Knowledge tacitness refers to the degree of difficulty that employees have in articulating and transferring knowledge. It is a function of complexity, uncertainty, resistance to codification or ambiguity ${ }^{[10,33]}$. As D'Eredita and Barreto ${ }^{[34]}$ contend, when the knowledge is tacit, it is highly personal and context-specific. Hence, it cannot be acquired if the related context information is insufficient. Most researchers suggest that tacit knowledge constitutes elements that are inarticulate, that is, we know more than we can tell ${ }^{[4]}$. However, not all knowledge is completely tacit. To the degree of its tacitness, knowledge can be learned or extracted, thus making organizational knowledge creation possible ${ }^{[9,35]}$.

Tacit knowledge includes the subconscious nature of tacit knowing, is hard to communicate, and often socially embedded and based on personal experiences ${ }^{[36-38]}$. According to Nonaka and Takeuchi ${ }^{[9]}$, tacit knowledge contains an important cognitive dimension residing in the employee's mind and consisting of mental models, beliefs, perceptions and schemata, which in turn are embedded in employee's cultural context. Because all knowledge possesses a tacit dimension that is difficult to articulate, we usually know a person's face, and can recognize it among a thousand, even among a million, yet we usually cannot tell how we recognize a face we know ${ }^{[4]}$. Some empirical research has explored the relationship between the tacitness of knowledge and the knowledge sharing process, Zander and Kogut ${ }^{[33]}$ found that the codified knowledge transfers faster than tacit knowledge, a similar point was made by Lord and Ranft ${ }^{[39]}$, Inkpen and Dinur ${ }^{[40]}$, who proposed there is a negative relationship between the tacitness of knowledge and efficiency of knowledge sharing.

When knowledge is more tacit, it is more difficult to share. Therefore, knowledge tacitness is an obstacle to an employee's socialization behavior. Tacitness also decreases an employee's ability to express, summarize, and view explicitly the knowledge they have through exchange and synthesis, thus preventing externalization behavior. Moreover, because knowledge tacitness impedes the relative capacity and effectiveness of employees to acquire and internalize 
relation-specific knowledge, it will negatively relate to knowledge internalization behavior. Accordingly, tacitness will decrease the three tacit knowledge sharing behaviors. Based on the above discussion, we predict the followings:

H3a: Knowledge tacitness will have a negative effect on employees' socialization behavior in tacit knowledge sharing.

H3b: Knowledge tacitness will have a negative effect on employees' externalization behavior in tacit knowledge sharing.

H3c: Knowledge tacitness will have a negative effect on employees' internalization behavior in tacit knowledge sharing.

\subsection{IT Support}

IT provides relative infrastructure and capability to facilitate knowledge flow smoothly within an organization. By accelerating knowledge related activities, such as searching, communicating, transferring, and integrating between employees, IT can improves knowledge sharing and organizational performance ${ }^{[41,42]}$.

Previous studies have shown that IT is an important factors influencing KM infrastructure, and contributes significantly to the knowledge sharing process ${ }^{[33,44]}$. As Hildreth ${ }^{[45]}$ maintained, the sharing of tacit knowledge is important for maintaining a distributed community, and IT can enable tacit knowledge sharing. In contrast, Alavi and Leidner ${ }^{[42]}$ show IT can encourage and facilitate knowledge sharing by using tools, such as corporate intranets, databases, and document management systems. Therefore, IT enables an employee to develop knowledge about how to communicate one's own ideas and integrate them into the ideas of others, and facilitates the process of knowledge sharing by enabling the creation, dissemination, and use of knowledge ${ }^{[46,47]}$.

It is generally believed that IT can promote tacit knowledge sharing. For example, IT provides employees in the organization access to the right information quickly and effectively ${ }^{[48]}$, and IT can also be used to catalogue the expertise of organizational employees, which facilitate employee's access to the right people, thus enhancing knowledge sharing ${ }^{[49]}$. Certain systems, e.g., groupware and collaborative system, provide a virtual space where employees can process tacit knowledge in real time, providing a greater chance for meaningful interaction ${ }^{[4,50]}$. In addition, exchange space is an ideal place to develop innovative and creative behaviors around problems and situations. One of the most important characteristics of these systems and exchange space is that they are founded on the democratization of knowledge. Therefore, IT enables employees to coordinate, and quickly disseminate and sharing tacit knowledge.

IT also facilitates the standardization and automation of certain tasks, supporting an employee's internalization behavior in tacit knowledge sharing. Through internet and groupware, employees can communicate and exchange ideas, thus promoting socialization behavior. And an employee's externalization behavior can easily occur with the use of knowledge mapping, as a result, facilitates the transfer of tacit knowledge into explicit knowledge. Based on the above discussion, we predict the followings:

H4a: IT support will have a positive effect on employees' socialization behavior in tacit knowledge sharing.

H4b: IT support will have a positive effect on employees' externalization behavior in tacit 
knowledge sharing.

H4c: IT support will have a positive effect employees' internalization behavior in tacit knowledge sharing.

\section{Research Methodology}

\subsection{Sample Characteristics and Data Collection}

To empirically test the proposed research model, a survey methodology was used. The questionnaire items, shown in Appendix A, were adapted from previously validated measures. Trust was measured by adapting Renz ${ }^{[20]}$ and Liu et al. ${ }^{[51]}$. Self-efficacy was measured with the scale developed by Compeau and Higgins ${ }^{[52]}$, and Hsu et al. ${ }^{[53]}$. Knowledge tacitness was based on the variables provided by Subramaniam and Venkatraman ${ }^{[54]}$. IT support measurements were adapted from the work of Tippins and Sohi ${ }^{[55]}$. Knowledge socialization behavior, externalization behavior and internalization behavior items were developed based on Hendriks ${ }^{[56]}$, Bock and $\mathrm{Kim}^{[31]}$.

All variables were measured on 5-point Likert scales where 1 means "strongly disagree" and 5 means "strong agree". The English to Chinese translation accuracy was insured by having two independent translators first translate and then back-translate the items. We selected employees working on complex product development projects as respondents. Complex products and systems are high cost, engineering-intensive products and systems custom-made for clients. Complex products projects are often developed by many key stakeholders including integrators, contractors, buyers, suppliers, and in most cases, the government. Hence, how to sharing tacit knowledge among key stakeholders is vital to the success of complex product development.

The measures' face validity was validated by interviewing nine experienced complex product development workers from three enterprises in China. These interviews allowed the authors to modify the survey items and rectify any potential problems. A pre-test was undertaken with 50 MBA students in a major Chinese university, and minor adjustments were made on the basis of specific suggestions. Finally, the refined questionnaire was issued to 400 knowledge workers who work on complex product development projects in companies located in six major and big province locations in China - Shaanxi, Beijing, Guangzhou, Sichuan, Hubei, and Guizhou.

A total of 258 useable responses were collected, resulting in a response rate of $64.5 \%$. Among the 258 respondents, approximately $63 \%$ are male, and $37 \%$ are female. Most respondents' job tenure $(42.64 \%)$ is from 4 to 6 years, $5.81 \%$ is under 2 years, $26.74 \%$ is from 2 to 4 years, $18.22 \%$ is from 6 to 8 years, and $6.59 \%$ is greater than 8 years. About $15.89 \%$ responses come from $\mathrm{R} \% \mathrm{D}$ organizations, $17.44 \%$ from manufacturing enterprises, $14.34 \%$ from sub-contractors, $13.57 \%$ from suppliers, $6.98 \%$ from government agencies, and the rest from other types of organizations.

\subsection{Reliability and Validity Analysis}

The reliability of the measures was analyzed using Cronbach's alpha coefficients. As Table 1 shows, all of the reliability coefficients are above 0.70 and considered acceptable ${ }^{[57]}$. Convergent validity was shown to be adequate since: 1) The average variance extracted (AVE) was 0.7 or better for all latent variables (Table 1); 2) The factor loadings of the items on their substantive 
construct are high (above 0.60) and significant. Discriminant validity was deemed satisfactory because: 1) The square root of each construct's AVE is greater than the correlations between the construct and other constructs (Table 1); 2) Each item's loading on its substantive construct is much greater than its cross-loadings on other constructs (Table 2).

Table 1 Reliability, AVE, and correlations

\begin{tabular}{cccccccccc}
\hline & $\alpha$ & AVE & trust & SE & KT & ITS & SB & EB & IB \\
\hline trust & 0.91 & 0.79 & $\mathbf{0 . 8 9}$ & & & & & & \\
SE & 0.82 & 0.74 & 0.48 & $\mathbf{0 . 8 6}$ & & & & & \\
KT & 0.92 & 0.87 & -0.49 & -0.51 & $\mathbf{0 . 9 3}$ & & & & \\
ITS & 0.83 & 0.75 & 0.54 & 0.58 & -0.59 & $\mathbf{0 . 8 7}$ & & & \\
SB & 0.92 & 0.80 & 0.59 & 0.54 & -0.50 & 0.59 & $\mathbf{0 . 8 9}$ & & \\
EB & 0.90 & 0.76 & 0.62 & 0.60 & -0.57 & 0.65 & 0.58 & $\mathbf{0 . 8 7}$ & \\
IB & 0.91 & 0.78 & 0.58 & 0.55 & -0.62 & 0.63 & 0.59 & 0.60 & $\mathbf{0 . 8 8}$ \\
\hline
\end{tabular}

Note: SE-self efficacy; KT-knowledge tacitness; ITS-IT support; SB-socialization behavior;

EB-Externalization behavior; IB-Internalization behavior; square roots of AVEs are bold on diagonal.

\subsection{Analytical of Model Fitting}

Structural equation modeling (SEM) was used to test the research model. Specifically, the AMOS software package was used. First, we estimated the fit of the research model ${ }^{[58]}$. Going beyond Chi-square statistics, overall fit measures evaluate how well a model reproduces the observed variables' covariance matrix. For models with good fit, Chi-square normalized by degrees of freedom $\left(\chi^{2} / \mathrm{df}\right)$ should not exceed three; the goodness-of-fit index (GFI), the adjusted goodness-of-fit index (AGFI), and the comparative fit index (CFI) should have a minimum value of 0.9 ; and the root mean-square error of approximation (RMSEA) value should not exceed $0.05^{[59]}$. The model fitting results show acceptable values of $\chi^{2} / \mathrm{df}$ (1.29), GFI (0.91), CFI (0.98), and RMSEA (0.033). AGFI is 0.89 , slightly lower than the commonly cited threshold but still acceptable.

\subsection{Hypotheses Testing and Results}

The path significance of each hypothesized association in the research model and the variance explained (R2) in each endogenous variables are examined. The results are presented in Figure 2 .

As Figure 2 shows, the link between trust and socialization behavior was positive and significant $(\beta=0.29, p<0.01)$, supporting H1a. The significant path between trust and externalization behaviors in tacit knowledge sharing provided support to $\mathrm{H} 1 \mathrm{~b}$ ( $\beta=0.26, p<$ 0.01). Trust is significantly related to internalization tacit knowledge sharing behaviors, hence $\mathrm{H} 1 \mathrm{c}$ is confirmed $(\beta=0.20, p<0.01)$. 
Table 2 Factor loadings and cross-loadings

\begin{tabular}{|c|c|c|c|c|c|c|c|}
\hline & trust & $\mathrm{SE}$ & $\mathrm{KT}$ & ITS & SB & $\mathrm{EB}$ & IB \\
\hline trust1 & 0.748 & 0.190 & 0.020 & 0.153 & 0.210 & 0.195 & 0.259 \\
\hline trust2 & 0.814 & 0.111 & 0.171 & 0.200 & 0.222 & 0.161 & 0.149 \\
\hline trust3 & 0.796 & 0.150 & 0.135 & 0.063 & 0.207 & 0.229 & 0.168 \\
\hline trust4 & 0.787 & 0.104 & 0.206 & 0.134 & 0.199 & 0.178 & 0.165 \\
\hline SE1 & 0.178 & 0.686 & 0.200 & 0.142 & 0.149 & 0.151 & 0.163 \\
\hline SE2 & 0.146 & 0.764 & 0.080 & 0.092 & 0.228 & 0.240 & 0.137 \\
\hline SE3 & 0.141 & 0.780 & 0.194 & 0.227 & 0.170 & 0.202 & 0.267 \\
\hline $\mathrm{KT} 1$ & -0.141 & -0.193 & -0.810 & -0.160 & -0.135 & -0.159 & -0.245 \\
\hline $\mathrm{KT} 2$ & -0.211 & -0.164 & -0.795 & -0.179 & -0.191 & -0.224 & -0.260 \\
\hline KT3 & -0.146 & -0.139 & -0.808 & -0.175 & -0.200 & -0.222 & -0.241 \\
\hline ITS1 & 0.192 & 0.110 & 0.172 & 0.742 & 0.263 & 0.212 & 0.215 \\
\hline ITS2 & 0.218 & 0.196 & 0.236 & 0.564 & 0.238 & 0.265 & 0.246 \\
\hline ITS3 & 0.171 & 0.255 & 0.199 & 0.765 & 0.166 & 0.245 & 0.182 \\
\hline SB1 & 0.196 & 0.151 & 0.128 & 0.204 & 0.796 & 0.171 & 0.211 \\
\hline SB2 & 0.202 & 0.194 & 0.203 & 0.176 & 0.722 & 0.183 & 0.134 \\
\hline SB3 & 0.260 & 0.159 & 0.093 & 0.105 & 0.766 & 0.106 & 0.226 \\
\hline SB4 & 0.208 & 0.146 & 0.166 & 0.149 & 0.838 & 0.218 & 0.222 \\
\hline EB1 & 0.162 & 0.203 & 0.163 & 0.255 & 0.228 & 0.732 & 0.120 \\
\hline EB2 & 0.320 & 0.191 & 0.196 & 0.193 & 0.251 & 0.652 & 0.213 \\
\hline EB3 & 0.232 & 0.265 & 0.193 & 0.145 & 0.136 & 0.681 & 0.293 \\
\hline EB4 & 0.224 & 0.155 & 0.194 & 0.166 & 0.154 & 0.811 & 0.183 \\
\hline IB1 & 0.158 & 0.181 & 0.239 & 0.140 & 0.196 & 0.182 & 0.740 \\
\hline IB2 & 0.229 & 0.179 & 0.206 & 0.220 & 0.204 & 0.128 & 0.753 \\
\hline IB3 & 0.200 & 0.186 & 0.185 & 0.148 & 0.211 & 0.277 & 0.695 \\
\hline IB4 & 0.226 & 0.151 & 0.240 & 0.143 & 0.245 & 0.165 & 0.793 \\
\hline
\end{tabular}

The relationship for self-efficacy and socialization behavior is not statistically significant ( $\beta=0.10, p>0.1$ ), thus $\mathrm{H} 2 \mathrm{a}$ is not supported. As predicted, higher self-efficacy leads to more externalization behavior $(\beta=0.18, p<0.01)$ and internalization behavior $(\beta=0.19, p<0.01)$ in tacit knowledge sharing, which support $\mathrm{H} 2 \mathrm{~b}$ and $\mathrm{H} 2 \mathrm{c}$.

No significant relationship is found between knowledge tacitness and socialization behavior $(\beta=-0.10, p>0.1)$, hence failing to support H3a. As expected, knowledge tacitness is significantly related to both externalization and internalization behavior in tacit knowledge sharing, supporting H3b $(\beta=-0.15, p<0.05)$ and H3c $(\beta=-0.29, p<0.01)$.

Finally, the results show that IT support is positively associated with socialization behavior $(\beta=0.34, p<0.01)$, externalization behavior $(\beta=0.38, p<0.01)$, and internalization behavior $(\beta=0.25, p<0.01)$, supporting $\mathrm{H} 4 \mathrm{a}, \mathrm{H} 4 \mathrm{~b}$ and $\mathrm{H} 4 \mathrm{c}$. 
The model explained a substantial amount of variance in the three dependent variables. First, $52 \%$ of the variance in socialization behavior is explained by trust and IT support. Furthermore, $69 \%$ of variance in externalization behavior and about $61 \%$ of variance in internalization behavior is accounted for by the four antecedents.

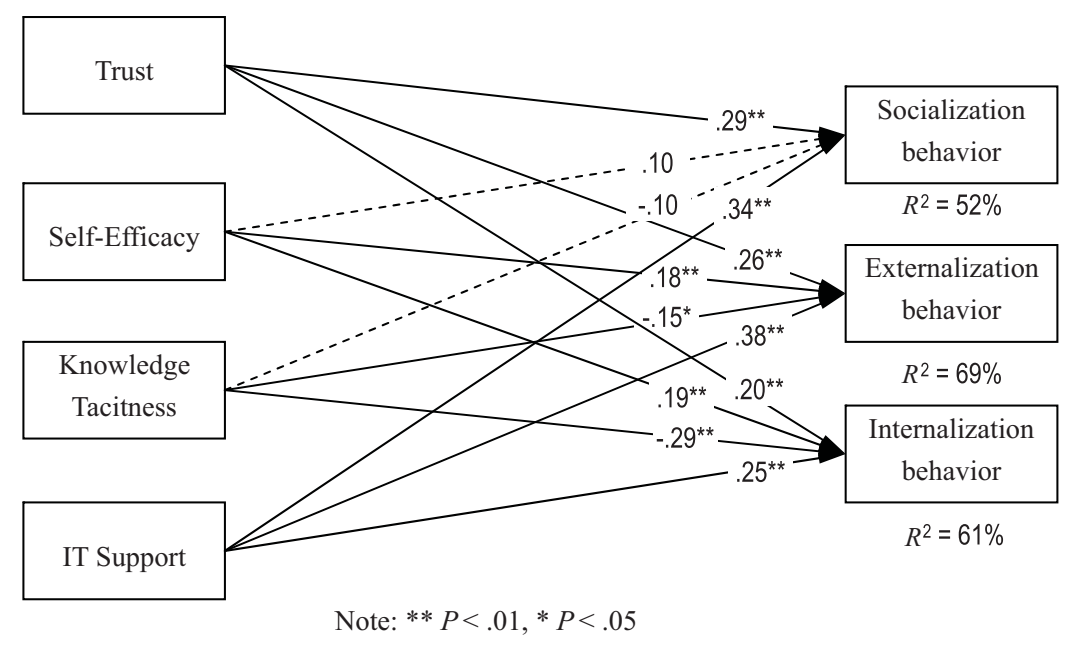

Figure 2 Model testing results

\section{Discussions}

\subsection{Major Findings}

As suggested by the previous literature, tacit knowledge sharing is affected by many factors. This study investigated tacit knowledge sharing among employees from the personal, interpersonal, knowledge based, and IT based perspectives. The results are discussed in the following section.

First, the findings of this study indicated that trust had a significant impact on knowledge socialization behavior, externalization behavior, and internalization behavior. Employees who trust each other can establish better relationships, and then they are more willing to share relevant ideas and information, as well as to clarify goals and problems. Trust between employees is an essential attribute in organizational culture, which is believed to have a strong influence on tacit knowledge sharing. Thus, trust is known as an employee's confidence in the reliability of the promise or actions of other employees ${ }^{[60]}$, and employees require the existence of trust in order to respond easily and share their knowledge. When there is high trust in employees' relationships, they become more willing to participate in tacit knowledge sharing.

Second, the study shows that self-efficacy plays an important role in the tacit knowledge sharing activities. Self-efficacy has a positive effect on externalization behavior and internalization behavior. According to Bandura ${ }^{[28]}$, self-efficacy is the judgment of one's capability to organize certain behaviors. It is concerned not only with the skills employees have, but also with their judgment of what they can do with those skills. For example, employees assess their self-efficacy based on their environment, personal goals and the relationship they find themselves in. Hence, one may formulate a degree of self-efficacy depending on the expectation of the outcomes. Employees may have higher assessments of their knowledge exchange self-efficacy, 
when there is cooperation within the environment and good relationship in which they find themselves.

Third, most previous studies focused only on the antecedents of knowledge tacitness, and the relationship between knowledge tacitness and knowledge sharing has received tremendous attention. However, the effects of knowledge tacitness on the knowledge sharing behavior have never been clearly addressed. The results show that knowledge tacitness has a negative effect on both knowledge externalization behavior and internalization behavior. This indicates it is difficult to imitate and transfer tacit knowledge among employees. Because tacit knowledge is unique and relatively less mobile, it becomes the basis of organizations' competitive advantage $^{[61]}$. These points out the need for organizations to concentrate their efforts on facilitating tacit knowledge transfer. If organizations successfully share tacit knowledge, it could play a vital role in building and sustaining organizations' competitive advantage ${ }^{[62]}$.

Finally, the literature suggests that IT support has a positive effect on knowledge sharing, however, previous research has not examined the specific effect of IT support on each of the employee's tacit knowledge sharing behavior. One of the main contributions of this study has been to analyze the impact of IT support on these three tacit knowledge sharing behavior. The results showed the significant influence of IT support on employee levels of tacit knowledge sharing behavior. Higher levels of IT support positively influences tacit knowledge sharing between employees. This leads to the conclusion that IT support has an important role in facilitating all three tacit knowledge sharing behaviors: Socialization behavior, externalization behavior and internalization behavior.

\subsection{Theoretical Implications}

This study makes several theoretical contributions. First, this study empirically examines employees' tacit knowledge sharing behavior. Although past research has discussed the importance of tacit knowledge sharing, relatively few empirical studies have examined tacit knowledge sharing behavior. Second, we decomposed tacit knowledge sharing into three behaviors: socialization behavior, externalization behavior, and internalization behavior. These specific behaviors describe how tacit knowledge sharing behavior occurs at the individual level in a more refined way. Third, we propose that tacit knowledge sharing can be understood from four perspectives: Personal, interpersonal, knowledge based, and IT based perspectives, and we selected one factor from each perspective to examine its impact on the three tacit knowledge sharing behaviors. The results demonstrate that the four factors can explain over $50 \%$ of variance in each of the behaviors. These findings suggest that powerful explanations of tacit knowledge sharing can be obtained by studying factors in the four perspectives we proposed. Future research can extend this research to investigate the impact of other factors in the four perspectives on tacit knowledge sharing.

\subsection{Practical Implications}

From a practical viewpoint, the results of our study have implications for managers to promote employees' tacit knowledge sharing behaviors. First, trust helps eliminate resistance to tacit knowledge sharing, and without trust the cooperation required for successful tacit knowledge sharing might be difficult to attain. Therefore, a climate of trust among employees is a 
basic condition that allows tacit knowledge to be shared, and manager should create a shared social and cultural context that cultivates a high degree of trust existence. Second, since selfefficacy plays a vital role in facilitating employees' tacit knowledge sharing, managers should provide valuable feedback and information to improve employees' self-efficacy. Training on leadership, teamwork, and communication skills should be offered to employees to improve their self-efficacy in externalization and internalization behaviors. Third, since knowledge tacitness is negatively related to employees' tacit knowledge sharing, it is important for organizations to identify the most tacit knowledge and design communication mechanism to enhance the sharing of such knowledge. Our findings suggest that the most effective way is likely to be socialization behavior, because such knowledge is difficult to externalize and internalize. Finally, organizations need to be aware that IT plays an important role in supporting tacit knowledge sharing, and adequately fund it, so that tacit knowledge can be efficiently shared among employees.

\subsection{Limitations}

The study is in some regards limited. First, because the survey sample was drawn from Chinese companies, the results of this study may not be generalizable to other countries. Second, there may be common method bias, because the survey asked the same respondents about both independent and dependent variables. If knowledge sharing behavior as a dependent variable can be measured via objective measurements, such problems may be decreased substantially. Finally, because the data in our study was cross-sectional and not longitudinal in nature, some causal relationships could only be inferred, rather than empirically supported. Confidence in the relationships among the constructs will be further enhanced by future studies that make use of other research methods. Future studies can consider longitudinal designs that will make it possible to understand better the factors influencing of employee's tacit knowledge sharing behavior.

\section{References}

[1] Wiig K. People-focused knowledge management: How effective decision making leads to corporate success. Burlington, MA: Elsevier Butterworth-Heinemann, 2004.

[2] Marshall A. Principles of economics. Macmillan, London, 1965.

[3] Szulanski G, Jensen R J. Presumptive adaptation and the effectiveness of knowledge transfer. Strategic Management Journal, 2006, 27(10): 937-957.

[4] Polanyi M. The tacit dimension. M E Sharp Inc, NY, 1967.

[5] Botkin J, Seeley C. The knowledge management manifesto. Knowledge Management Review, 2001, 3(6): $6-21$.

[6] Koh J, Kim Y G. Knowledge sharing in virtual communities: An e-business perspective. Expert Systems with Application, 2004, 26(2): 155-166.

[7] Haas M R, Hansen M T. Different knowledge, different benefits: Toward a productivity perspective on knowledge sharing in organizations. Strategic Management Journal, 2007, 28(11): 1133-1153.

[8] Syed Ikhsan S O S, Rowland F. Benchmarking knowledge management in a public organisation in Malaysia. Benchmarking: An International Journal, 2004, 11(3): 238-266.

[9] Nonaka I, Takeuchi H. The knowledge-creating company. Oxford University Press, New York, 1995.

[10] Szulanski G. The process of knowledge transfer: A diachronic analysis of stickiness. Organizational Behavior and Human Decision Processes, 2000, 82(3): 9-27.

[11] Joshi K D, Sarker S, Sarker S. Knowledge transfer within information systems development teams: Examining the role of knowledge source attributes. Decision Support Systems, 2007, 43(2): 322-335. 
[12] Holste J S. A study of the effects of affect-based trust and cognition-based trust on intra-organizational knowledge sharing and use. Ph.D. Dissertation, Regent University, Virginia Beach, Virginia, 2003.

[13] Srivastava R K. The resource-based view and marketing: The role of market-based assets in gaining competitive advantage. Journal of Management, 2001, 27(6): 777-802.

[14] Disterer G. Fostering knowledge sharing: Why and how? Paper presented at the IADIS International Conference e-Society, 2003.

[15] Mayer R C, Davis J H, Schoorman F D. An integrative model of organizational trust. Academy of Management Review, 1995, 20(3): 709-734.

[16] Kalantzis M, Cope B. Linking trust, values and perceived benefits. International Conference on Knowledge Management, 2003, 7-9 July, Putra World Trade Centre, Kuala Lumpur, Malaysia, [Online] Available: http://ickm.upm.edu.my/schedule.html (August 12, 2008).

[17] Holste J S, Fields D. Trust and tacit knowledge sharing and use. Journal of Knowledge Management, 2010, 14(1): 128-140.

[18] Yang S C, Farn C K. Social capital, behavioural control, and tacit knowledge sharing - A multi-informant design. International Journal of Information Management, 2009, 29(3): 210-218.

[19] Nelson K M, Cooprider J G. The contribution of shared knowledge to IS group performance. MIS Quarterly, 1996, 21(4): 409-429.

[20] Renzl B. Trust in management and knowledge sharing: The mediating effects of fear and knowledge documentation. Omega, 2008, 36(2): 206-220.

[21] Choi F Y Y. Advances in domain independent linear text segmentation. In Proceedings of NAACL-00, 2000, 26-33.

[22] Epstein L D. Sharing knowledge in organizations: How people use media to communicate. Unpublished dissertation, University of California, Berkeley, CA, 2000.

[23] Chiu C M, Hsu M H, Wang E T G. Understanding knowledge sharing in virtual communities: An integration of social capital and social cognitive theories. Decision Support System, 2006, 42(3): 1872-1888.

[24] Koskinen K U, Pihlanto P, Vanharanta H. Tacit knowledge acquisition and sharing in a project work context. International Journal of Project Management, 2003, 21(4): 281-290.

[25] Ormrod J. Educational psychology developing learners. Pearson Education, New Jersey, 2006.

[26] Bandura A, Locke E A. Negative self-efficacy and goals revisited. Journal of Applied Psychology, 2003, 88(1): 87-99.

[27] Chen C J, Hung S W. To give or to receive? Factors influencing members' knowledge sharing and community promotion in professional virtual communities. Information \& Management, 2010, 47(4): 226-236.

[28] Bandura A. Self-efficacy: The exercise of control. Freeman, New York, 1997.

[29] Elias H, Noordin N, Mahyuddin R H. Achievement, motivation and self efficacy in relation to adjustment among university students. Journal of Social Sciences, 2010, 6(3): 333-339.

[30] Oliver T A, Shapiro F. Self-efficacy and computers. Journal of Computer-Based Interactions, 1993, 20(3): 81-85.

[31] Bock G W. Kim Y G. Breaking the myths of rewards: An exploratory study of attitudes about knowledge sharing. Information Resources Management Journal, 2002, 15(2): 14-21.

[32] Endres M L, Endres S P, Chowdhury S K, et al. Tacit knowledge sharing, self-efficacy theory, and application to the open source community. Journal of Knowledge management, 2007, 11(3): 92-103.

[33] Zander U, Kogut B. Knowledge and the speed of the transfer and imitation of organizational capabilities: An empirical test. Organization Science, 1995, 6(1): 76-92.

[34] D'Eredita M A, Barreto C. How does tacit knowledge proliferate? An episode-based perspective. Organization Studies, 2006, 27(12): 1821-1841.

[35] Leonard D, Sensipe S. The role of tacit knowledge in group innovation. California Management Review, 1998, 40(3): 112-131.

[36] Von Hippel E. Sticky information and the locus of problem solving: Implications for innovation. Management Science, 1994, 40(4): 429-439.

[37] Nonaka I. A dynamic theory of organizational knowledge creation. Organization Science, 1994, 5(1): 14-37.

[38] Osterloch M, Frey B. Motivation, knowledge transfer and organizational forms. Organization Science, 2000, 11(5): 538-550.

[39] Lord M D, Ranft A L. Transfer and sharing of local knowledge within the firm and entry into new interna- 
tional markets. Academy of Management Best Papers Proceedings, 1998.

[40] Inkpen A C, Dinur A. Knowledge management processes and international joint-ventures. Organization Science, 1998, 9(4): 454-468.

[41] Lee S M, Hong S. An enterprise-wide knowledge management system infrastructure. Industrial Management \& Data Systems, 2002, 102(1): 17-25.

[42] Alavi M, Leidner D E. Review: Knowledge management and knowledge management systems: Conceptual foundations and research issues. MIS Quarterly, 2001, 25(1): 107-136.

[43] Constant D, Sproull L, Kiesler S. The kindness of strangers: The usefulness of electronic weak ties for technical advice. Organization Science, 1996, 7(2): 119-135.

[44] Coff R W, Coff C D, Eastvold R. The knowledge-leveraging paradox: How to achieve scale without making knowledge imitable. Academy of Management Review, 2006, 31(2): 452-465.

[45] Hildreth P M. Going virtual: Distributed communities of practice. Idea Group Publishing, 2004.

[46] Majchrzak A, Malhotra A, John R. Perceived individual collaboration know-how development through information technology-enabled contexualization: Evidence from distributed teams. Information Systems Research, 2005, 16(1): 9-27.

[47] Davenport T H, Prusak L. Working knowledge: How organizations manage what they know. Harvard Business School Press, Boston, MA, 1998.

[48] Hope J, Hope T. Competing in the third wave. Harvard Business School Press, Boston, MA, 1997.

[49] Al-Hawamdeh S. Knowledge management: Re-thinking information management and facing the challenge of managing tacit knowledge. Information Research, 2002, 8(1), http:// InformationR.net/ir/81/paper143.html.

[50] Marwick A. Knowledge management technology. IBM Systems Journal, 2001, 40(4): 814-830.

[51] Liu C, Marchewka J T, Lu J, et al. Beyond concern - A privacy-trust behavioral intention model of electronic commerce. Information \& Management, 2005, 42(2): 289-304.

[52] Compeau D R, Higgins C A. Computer self-efficacy: Development of a measure and initial test. MIS Quarterly, 1995, 19(2): 189-211.

[53] Hsu M H, Ju T L, Yen C H, et al. Knowledge sharing behavior in virtual communities: The relationship between trust, self-efficacy, and outcome expectations. International Journal of Human-Computer Studies, 2007, 65(11): 153-169.

[54] Subramaniam M, Venkatraman N. Determinants of transnational new product development capability: Testing the influence of transferring and deploying tacit overseas knowledge. Strategic Management Journal, 2001, 22(4): 359-378.

[55] Tippins M J, Sohi R S. IT competency and firm performance: Is organizational learning a missing link? Strategic Management Journal, 2003, 24(8): 745-761.

[56] Hendriks P. Why share knowledge? The influence of ICT on motivation for knowledge sharing. Knowledge and Process Management, 1999, 6(2): 91-100.

[57] Nunnally J. Psychometric theory. 2nd ed. McGraw-Hill, New York, 1978.

[58] Hair J F J, Anderson R E, Tatham R L, et al. Multivariate data analysis. 5th ed. Englewood Cliffs, NJ: Prentice-Hall, 1998.

[59] Hu L, Bentler P M. Cutoff criteria for fit indexes in covariance structure analysis: Conventional criteria versus new alternatives. Structural Equation Modeling: A Multidisciplinary Journal, 1999, 6: 1-55.

[60] Politis J D. Power and knowledge acquisition: The implications for team performance. In the Proceedings of the Conference on Organisational Knowledge, Learning and Capabilities (OKLC), IESE Business School, University of Navarra, Barcelona, Spain, 13-14 April, 2003.

[61] Grant R. Prospering in dynamically-competitive environments: Organizational capability as knowledge integration. Organization Science, 1996, 7(4): 375-387.

[62] Carlile P R. Transferring, translating, and transforming: An integrative framework for managing knowledge across boundaries. Organization Science, 2004, 15(5): 555-568.

\section{APPENDIX}

Trust

1. I believe the help I give to others will be returned in the future. 
2. Generally speaking, I can trust others to do what they say they will.

3. Others can be relied upon if I come across critical incidents.

4. Our team members trust each other.

Self-efficacy

1. I am confident about my ability in providing my experiences, insights and expertise.

2. I am confident that I am able to communicate my ideas and perspectives to others.

3. I am confident in articulating myself in written, verbal and symbolic forms.

Knowledge tacitness

In general, the knowledge used our projects is difficult

1. . . to comprehensively document in manuals and reports.

2. $\cdots$ to precisely communicate through written documents.

3. $\cdots$ to understand without personal experiences.

IT support

1. IT is widely utilized by members in my organization to communicate.

2. IT is widely available for members in my organization to manage knowledge.

3. Members in my organization apply IT to search and use current organizational knowledge. Socialization behavior

1. I often talk about my job experience or know-how with other members.

2. I often tell others my expertise during group meetings.

3. I always try to interact with other members to solve problems at work.

4. I actively exchange ideas with colleagues.

Externalization behavior

1. I take the initiative to document my work-related knowledge.

2. After learning new skills useful to work, I explain it to let more people learn it.

3. I can translate jargons into everyday language to communicate with others.

4. I express my thoughts using example when others cannot understand.

Internalization behavior

1. I often use knowledge acquired from others to improve my skill level.

2. I always try to integrate new things I learned with past experiences.

3. I often apply newly learned knowledge to solve relevant problems at work.

4. I often collect new information and combine it with old information to generate new ideas. 